\title{
Regional Differences in Raindrop Size Distribution within Indian Subcontinent and Adjoining Seas as Inferred from Global Precipitation Measurement Dual-frequency Precipitation Radar
}

\author{
Basivi RADHAKRISHNA \\ National Atmospheric Research Laboratory, Department of Space, Govt. of India, India \\ Kadiri SAIKRANTHI \\ Department of Earth and Climate Science, Indian Institute of Science Education and Research (IISER) Tirupati, India \\ and \\ Thota Narayana RAO
}

National Atmospheric Research Laboratory, Department of Space, Govt. of India, India

(Manuscript received 20 June 2019, in final form 18 February 2020)

\begin{abstract}
Variations in raindrop size distribution (DSD) during the southwest monsoon (SWM) season over different climatic regions in the Indian subcontinent and adjoining seas are studied in this paper using five years (2014-2018) of global precipitation measurement dual-frequency precipitation radar derived DSDs. The rain rate $(R)$ stratified DSD measurements show clearly that land, sea, and orography differ in their mass-weighted mean diameter $\left(D_{m}\right)$ values. Irrespective of $R, D_{m}$ values of deep rain were found to be larger in continental rain than in maritime and orographic rain. However, for shallow storms, the $D_{m}$ values were smaller for continental rain than for orographic and maritime rain. Based on the $D_{m}$ values and their variations with $R$ of the deep systems, the regions could be categorized into four groups, within which the $D_{m}$ values were nearly equal: (1) the northwest India (NWI) and the southeast peninsular India (SEPI); (2) the foothills of the Himalayas (FHH) and the central India (CI); (3) the northeast India (NEI) and the Bay of Bengal (BOB); and (4) the Arabian Sea (AS), the Western Ghats (WG), and the Myanmar coast (MC). Compared to other geographical regions of the Indian subcontinent, the $D_{m}$ values of the deep systems were the largest over NWI and SEPI and the smallest over the WG, MC, and AS; while for shallow systems, the $D_{m}$ values were the largest over the BOB and AS and the smallest over the SEPI and NWI regions. Though the cloud drops were smaller over the continental regions, the raindrops were larger than in the maritime and orographic rain regions. The microphysical and dynamical processes that occur during precipitation play a vital role in altering the DSDs of continental rain.
\end{abstract}

Keywords raindrop size distribution; southwest monsoon; global precipitation measurement; dual-frequency precipitation radar

Corresponding author: Basivi Radhakrishna, National Atmospheric Research Laboratory, Department of Space, Government of India, Gadanki, Andhra Pradesh 517112, India

E-mail: rakibasivi@gmail.com

J-stage Advance Published Date: 26 March 2020

CThe Author(s) 2020. This is an open access article published by the Meteorological Society of Japan under a Creative Commons Attribution 4.0 International (CC BY 4.0) license (https://creativecommons.org/licenses/by/4.0). 
Citation Radhakrishna, B., K. Saikranthi, and T. N. Rao, 2020: Regional differences in raindrop size distribution within Indian subcontinent and adjoining seas as inferred from global precipitation measurement dual-frequency precipitation radar. J. Meteor. Soc. Japan, 98, 573-584, doi:10.2151/jmsj.2020-030.

\section{Introduction}

India has an agro-based economy and receives the majority of its annual rainfall during the south Asian monsoon season, also known as the southwest monsoon (SWM) season (spanning June to September). The monsoonal precipitating systems occur at large spatial scales, but exhibit significant spatiotemporal variability in terms of rainfall as well as the types of precipitating systems over the Indian subcontinent (Gadgil 2003; Goswami 2005; Rajeevan et al. 2010; Kulkarni et al. 2011; Saikranthi et al. 2013, 2014, 2018; Rao et al. 2016). These studies have demonstrated the importance of the climatologically homogeneous rainfall regions in various scientific and general applications. Romatschke et al. (2010), Saikranthi et al. (2014, 2018, 2019a, b), and Rao et al. (2016) demonstrated that precipitating systems characteristics were distinctly different in different climatic regions of India. For example, deep convective systems are dominant in the northeast India, in the foothills of the Himalayas $(\mathrm{FHH})$, and in the northern Bay of Bengal (BOB) regions, while shallow rain is predominant over the Arabian Sea (AS; see Fig. 1 for the geographical regions of India). The widespread stratiform rain dominates in the monsoon trough zone. Therefore, it can be assumed that the raindrop size distribution (DSD) also varies across the different climatic regions of the Indian subcontinent and the adjoining seas.

DSD is a fundamental property of rain and is essential in understanding the microphysical processes that occur at the different stages of a precipitating system. The large spatiotemporal variations in the characteristics of tropical precipitating systems (Houze et al. 2015; Saikranthi et al. 2018) produce differences in DSDs within the storm, from one storm to another and from season to season (Atlas et al. 1999; Tokay et al. 2002; Rao et al. 2001, 2009; Bringi et al. 2003; Rosenfeld and Ulbrich 2003; Kozu et al. 2006; Ulbrich and Atlas 2007; Kirankumar et al. 2008; Radhakrishna et al. 2009; Radhakrishna and Rao 2009, 2010). Spatiotemporal variations in DSDs have been studied extensively using various types of disdrometer measurements, mainly in the southern peninsula of India, the Western Ghats (WG), and Kolkata (Verma and Jha 1996; Rao et al. 2001, 2009; Reddy and Kozu 2003;
Maitra 2004; Suresh and Bhatnagar 2005; Kozu et al. 2006; Kirankumar et al. 2008; Radhakrishna et al. 2009; Radhakrishna and Rao 2009, 2010; Harikumar et al. 2010; Chakravarty and Raj 2013; Konwar et al. 2014; Lavanya et al. 2019). However, the characteristics of DSDs have not been explored in other regions of the Asian summer monsoon, mainly due to a lack of DSD measurements.

The DSDs derived from dual-frequency precipitation radars (DPR) aboard the global precipitation measurement (GPM) core satellite provide an opportunity to study their characteristics at any given region between $60^{\circ} \mathrm{N}$ and $60^{\circ} \mathrm{S}$ latitudes. The quality of the GPM-DPR derived DSD parameters, mass-weighted mean diameter $\left(D_{m}\right.$ in $\left.\mathrm{mm}\right)$, and normalized DSD scaling parameter for concentration $\left(N_{w}\right.$ in $\left.\mathrm{mm}^{-1} \mathrm{~m}^{-3}\right)$ have been assessed in ground validation studies at various geographical regions (Radhakrishna et al. 2016; Tokay et al. 2017; D'Adderio et al. 2018). Radhakrishna et al. (2016) showed that in the Gadanki region of southeast peninsular India (SEPI), the GPM-DPR derived $D_{m}$ values (version 3 ) could reproduce seasonal variations, although they were not as pronounced in the disdrometer measurements. On the other hand, $N_{w}$ has been found to agree poorly with disdrometer measurements, even at a seasonal scale. Tokay et al. (2017) interpolated DSDs obtained from two-dimensional video disdrometers to a grid scale of GPM-DPR $(5 \times 5$ $\mathrm{km}$ ) and compared the $D_{m}$ values over northern Oklahoma during GPM overpasses. Their analysis showed good agreement between the $D_{m}$ values obtained from the two datasets at a grid scale. D'Adderio et al. (2018) compared the $D_{m}$ values derived from ground-based C-band polarimetric radars and GPM-DPR over Italy and demonstrated that they were well matched, not only at the near surface clutter-free bin altitude but also at all other altitudes.

The aforementioned ground validation studies indicate the potential of GPM-DPR derived $D_{m}$ values to characterize DSDs over any given region of interest. The statistical characteristics of DSDs are crucial in the single-frequency (SF) retrieval algorithm, which uses climatological DSD variations in different climatic regions at a monthly scale. The present study is the first to utilize DSD measurements (as the observations are sparse over the Indian subcontinent) from 
GPM-DPR to assess the DSD variations for deep and shallow systems over different climatic zones of the Indian subcontinent and adjoining seas.

\section{Data}

The precipitation radars onboard the core satellite of the GPM constellation operate at Ku- $(13.6 \mathrm{GHz})$ and Ka-bands $(35.5 \mathrm{GHz})$ to yield the three-dimensional structure of precipitation (Hou et al. 2014). GPM-DPR reflectivity profiles are classified into three major types: convective, stratiform, and others, based on the existence of bright band and surface rain (Awaka et al. 2016). The convective and stratiform reflectivity profiles of surface rain and echo top height above $0^{\circ} \mathrm{C}$ isotherms are segregated in deep rain, which has both ice and liquid phases. On the other hand, the reflectivity profiles of surface rain and echo tops below $0^{\circ} \mathrm{C}$ isotherms are classified as shallow rain, which has only a liquid phase. The DSDs used in the present study were obtained from the lowest clutter-free bin of the GPM-DPR level 2 version 6 dataset between 2014 and 2018. SF and dual-frequency (DF) algorithms used to retrieve the DSDs from GPM-DPR were examined by Meneghini et al. (1997), Rose and Chandrasekar (2006), Seto and Iguchi (2011), Seto et al. (2013), Liao et al. (2014), and Radhakrishna et al. (2016), depending on the availability of the reflectivity pixels of the two radars. The $D_{m}$ values were identified using the attenuation $(k)$ to reflectivity $\left(Z_{e}\right)$ ratios in the SF algorithm and the $\mathrm{Ku}$ - to Ka-band reflectivity ratios in the DF algorithm. Mathematically, these ratios are represented as follows:

$$
\begin{aligned}
& \frac{k}{Z_{e}}=\frac{G\left(\lambda, \mu, D_{m}\right)}{F\left(\lambda, \mu, D_{m}\right)}, \\
& \operatorname{DFR}(d B)=10 \log _{10}\left(\frac{Z_{K u}}{Z_{K a}}\right)=10 \log _{10}\left[\frac{F\left(\lambda_{K u}, \mu, D_{m}\right)}{F\left(\lambda_{K a}, \mu, D_{m}\right)}\right],
\end{aligned}
$$

where $\mu$ denotes the shape factor of the gamma size distribution, $\lambda$ is the wavelength $(\mathrm{mm})$, and DFR represents the dual-frequency ratio. The terms $k$, $G\left(\lambda, \mu, D_{m}\right)$, and $F\left(\lambda, \mu, D_{m}\right)$ are defined as follows:

$$
\begin{aligned}
& k=N_{w} G\left(\lambda, \mu, D_{m}\right), \\
& F\left(\lambda, \mu, D_{m}\right) \\
& =\frac{\lambda^{4}}{\pi^{5}}\left|\frac{n_{w}^{2}+2}{n_{w}^{2}-1}\right|^{2} \int_{D_{\min }}^{D_{\max }} \sigma_{b}(D) f\left(D ; \mu, D_{m}\right) d D,
\end{aligned}
$$

$$
\begin{aligned}
& G\left(\lambda, \mu, D_{m}\right) \\
& =4.343 \times 10^{-3} \int_{D_{\min }}^{D_{\max }} \sigma_{e}(D) f\left(D ; \mu, D_{m}\right) d D .
\end{aligned}
$$

In the above equations, $D$ is the diameter of the raindrop $(\mathrm{mm}), n_{w}$ is the refractive index of water, $\sigma_{b}$ is the backscattering cross-section $\left(\mathrm{mm}^{2}\right)$, and $\sigma_{e}$ is the extinction cross-section $\left(\mathrm{mm}^{2}\right)$ of the raindrops at a given temperature. The term $f\left(D ; \mu, D_{m}\right)$ is obtained from the normalized gamma distribution (Testud et al. 2001) as follows:

$$
\begin{aligned}
& N(D)=N_{w} f\left(D ; \mu, D_{m}\right), \\
& f\left(D ; \mu, D_{m}\right) \\
& =\frac{6(\mu+4)^{(\mu+4)}}{4^{4} \Gamma(\mu+4)}\left(\frac{D}{D_{m}}\right)^{\mu} \exp \left[\frac{-(\mu+4) D}{D_{m}}\right],
\end{aligned}
$$

where $\Gamma$ denotes the mathematical gamma function. In the SF algorithm, the ratio mentioned in Eq. (1) is a monotonically decreasing function of $D_{m}$ as long as $D_{m}$ takes true values (Seto et al. 2013). However, in the DF algorithm, the DFR mentioned in Eq. (2) is a monotonically increasing function of $D_{m}$ when $D_{m}>1$ $\mathrm{mm}$ for a fixed $\mu(=3)$ value (Seto et al. 2013; Liao et al. 2014; Radhakrishna et al. 2016). Therefore, $D_{m}$ can be retrieved individually from either $k / Z_{e}$ or DFR, and $N_{w}$ is considered from the lookup tables using $Z_{e}$ values. In the present study, only near surface clutter free bin $D_{m}$ values greater than $1 \mathrm{~mm}$ were considered to avoid the data with retrieval errors.

The accumulated rainfall dataset was taken from the integrated multi-satellite retrievals for GPM (IMERG) version 5 (research/final run) with a spatial resolution of $0.1^{\circ} \times 0.1^{\circ}$ and a temporal resolution of 30 minutes between 2014 and 2018. More details on the technical aspects of the IMERG dataset can be found in Huffman et al. (2017). To understand the particle size distribution in the clouds, a moderate resolution imaging spectroradiometer (MODIS) AQUA satellite level 3 (MYD08) cloud effective radius (CER) liquid (Platnick et al. 2017) was used during the same period. The CER is the ratio of the third moment to the second moment of the particle size distribution (i.e., it represents the weighted mean of the size distribution of the cloud particles within a cloud column). The CER in the MODIS level 3 daily dataset is a collection of retrieved valid cloud products of level 2 data pixels within a calendar day. These pixels are first combined and are then gridded by weighting the respective ice/ liquid water cloud pixel counts within a $1^{\circ} \times 1^{\circ}$ spatial resolution. 


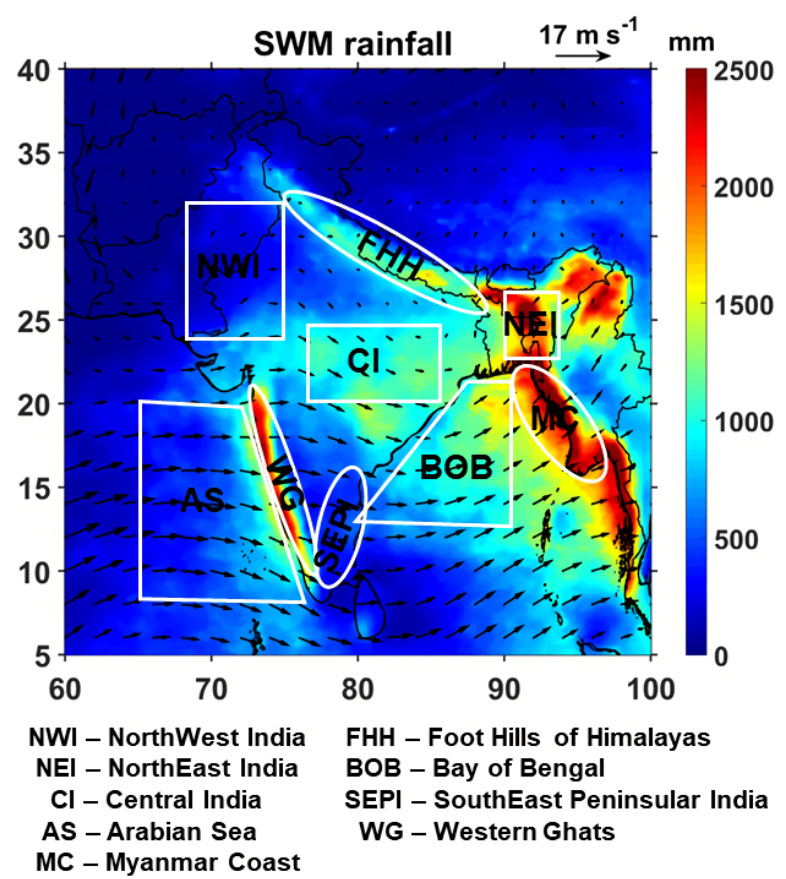

Fig. 1. Spatial distribution of the southwest monsoon season (from June to September) rainfall over the Indian subcontinent during the study period 2014 and 2018. The overlaid black arrow lines indicate the strength and the arrows indicate the direction of the wind at $850 \mathrm{hPa}$. The white closed boundaries specify different climatic zones considered in the present study.

In the present study, the different climatic zones of the Indian subcontinent are considered based on the work of Saikranthi et al. (2014). The regions were selected to ensure that the seasonal characteristics of precipitation were similar in a given region. The identified regions are shown in Fig. 1, with the approximate boundaries shown in white color. Figure 1 also depicts the SWM seasonal accumulated rainfall in shaded colors, the overlaid black arrow lines indicate the strength, and the arrows indicate the direction of the wind at $850 \mathrm{hPa}$. The Indian subcontinent is segregated into nine regions: two dry regions - the northwest India (NWI) and the southeast peninsular India (SEPI), the FHH, the Central India (CI) (the core monsoon zone), two oceanic regions - the $\mathrm{BOB}$ and the AS, two coastal regions - the WG and the Myanmar coast (MC), and the northeast India (NEI). The accumulated rainfall during the SWM season over the Indian subcontinent showed a large spatial variability, with the maximum rainfall over the NEI, MC, and

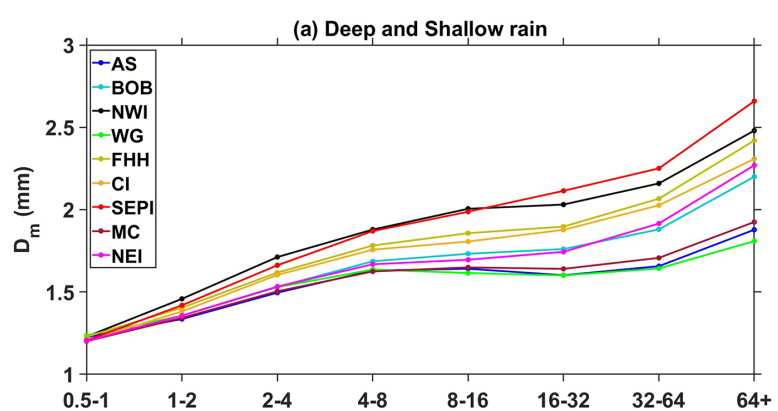

(b) Deep rain

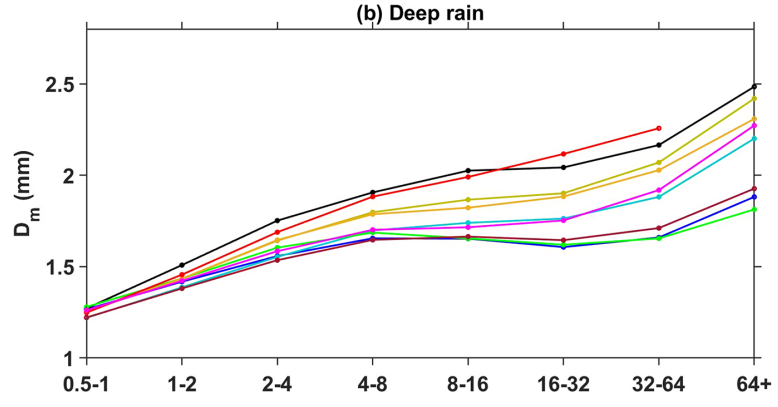

(c) Shallow rain

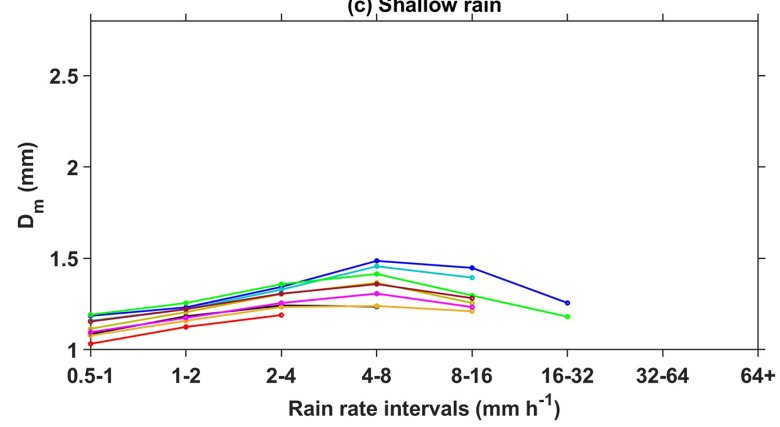

Fig. 2. (a) Near surface mean $D_{m}(\mathrm{~mm})$ at different rain rate intervals obtained from GPM-DPR during the SWM season in different climatic zones. (b) and (c) are the same as (a), but for deep and shallow precipitating systems, respectively.

WG regions and the minimum rainfall over the NWI region. SEPI, FHH, NEI, and NWI received the majority of their rainfall from deep convective systems, the $\mathrm{BOB}$ and $\mathrm{MC}$ from wide core convective regions, the CI from widespread systems, and the WG and AS from shallow systems (Houze et al. 2015; Saikranthi et al. 2013, 2018); therefore, the DSDs also demonstrate different characteristics over these regions.

\section{Results}

The $D_{m}$ values derived from GPM-DPR were grouped into eight rain rate intervals, following Radhakrishna et al. (2016). The mean $D_{m}$ values for each of 
Table 1. Number of rainy pixels used to estimate the mean $D_{m}$ shown in Fig. 2 for all types of rain (without parentheses), and the percentage occurrence of deep systems (within parentheses) and shallow systems (square brackets).

\begin{tabular}{|c|c|c|c|c|c|c|c|c|c|}
\hline $\begin{array}{l}\text { Rain rate } \\
\left(\mathrm{mm} \mathrm{h}^{-1}\right)\end{array}$ & AS & BOB & NWI & WG & FHH & CI & SEPI & $\mathrm{MC}$ & NEI \\
\hline $0.5-1$ & $\begin{array}{c}123622 \\
(50.4 \%) \\
{[49.6 \%]}\end{array}$ & $\begin{array}{c}122550 \\
(75.5 \%) \\
{[24.5 \%]}\end{array}$ & $\begin{array}{c}22754 \\
(76.9 \%) \\
{[23.1 \%]}\end{array}$ & $\begin{array}{c}39821 \\
(50.3 \%) \\
{[49.7 \%]}\end{array}$ & $\begin{array}{c}60269 \\
(80.3 \%) \\
{[19.7 \%]}\end{array}$ & $\begin{array}{c}66413 \\
(72.9 \%) \\
{[27.1 \%]}\end{array}$ & $\begin{array}{c}16619 \\
(80.4 \%) \\
{[19.6 \%]}\end{array}$ & $\begin{array}{c}47254 \\
(68.6 \%) \\
{[31.4 \%]}\end{array}$ & $\begin{array}{c}23427 \\
(64.6 \%) \\
{[35.4 \%]}\end{array}$ \\
\hline $1-2$ & $\begin{array}{c}108519 \\
(55.9 \%) \\
{[44.1 \%]}\end{array}$ & $\begin{array}{c}112320 \\
(81.5 \%) \\
{[18.5 \%]}\end{array}$ & $\begin{array}{c}22267 \\
(84.5 \%) \\
{[15.5 \%]}\end{array}$ & $\begin{array}{c}40255 \\
(55.7 \%) \\
{[44.3 \%]}\end{array}$ & $\begin{array}{c}53608 \\
(86.7 \%) \\
{[13.3 \%]}\end{array}$ & $\begin{array}{c}62739 \\
(80.9 \%) \\
{[19.1 \%]}\end{array}$ & $\begin{array}{c}14282 \\
(88.8 \%) \\
{[11.2 \%]}\end{array}$ & $\begin{array}{l}47120 \\
(76 \%) \\
{[24 \%]}\end{array}$ & $\begin{array}{c}22833 \\
(73.2 \%) \\
{[26.8 \%]}\end{array}$ \\
\hline $2-4$ & $\begin{array}{l}76612 \\
(71 \%) \\
{[29 \%]}\end{array}$ & $\begin{array}{c}93442 \\
(89.7 \%) \\
{[10.3 \%]}\end{array}$ & $\begin{array}{c}17715 \\
(92.2 \%) \\
{[7.8 \%]} \\
\end{array}$ & $\begin{array}{c}31324 \\
(69.6 \%) \\
{[30.4 \%]}\end{array}$ & $\begin{array}{c}40963 \\
(92.6 \%) \\
{[7.4 \%]} \\
\end{array}$ & $\begin{array}{c}49867 \\
(89.7 \%) \\
{[10.3 \%]}\end{array}$ & $\begin{array}{c}10397 \\
(94.7 \%) \\
{[5.3 \%]} \\
\end{array}$ & $\begin{array}{c}40840 \\
(86.3 \%) \\
{[13.7 \%]}\end{array}$ & $\begin{array}{c}18628 \\
(84.1 \%) \\
{[15.9 \%]}\end{array}$ \\
\hline $4-8$ & $\begin{array}{c}42663 \\
(85.3 \%) \\
{[14.7 \%]}\end{array}$ & $\begin{array}{c}59545 \\
(95.1 \%) \\
{[4.9 \%]}\end{array}$ & $\begin{array}{c}9567 \\
(95.9 \%) \\
{[4.1 \%]}\end{array}$ & $\begin{array}{c}17672 \\
(81.5 \%) \\
{[18.5 \%]}\end{array}$ & $\begin{array}{c}23009 \\
(96.4 \%) \\
{[3.6 \%]}\end{array}$ & $\begin{array}{c}26783 \\
(94.6 \%) \\
{[5.4 \%]}\end{array}$ & $\begin{array}{c}4694 \\
(98 \%) \\
{[2 \%]}\end{array}$ & $\begin{array}{c}26509 \\
(92.4 \%) \\
{[7.6 \%]}\end{array}$ & $\begin{array}{c}11525 \\
(91.6 \%) \\
{[8.4 \%]}\end{array}$ \\
\hline $8-16$ & $\begin{array}{c}16584 \\
(94.1 \%) \\
{[5.9 \%]}\end{array}$ & $\begin{array}{c}25019 \\
(97.8 \%) \\
{[2.2 \%]}\end{array}$ & $\begin{array}{c}4049 \\
(97.7 \%) \\
{[2.3 \%]}\end{array}$ & $\begin{array}{c}7506 \\
(89 \%) \\
{[11 \%]}\end{array}$ & $\begin{array}{c}9153 \\
(98.5 \%) \\
{[1.5 \%]}\end{array}$ & $\begin{array}{c}10355 \\
(97.4 \%) \\
{[2.6 \%]}\end{array}$ & $\begin{array}{c}1654 \\
(99.5 \%) \\
{[0.5 \%]}\end{array}$ & $\begin{array}{c}11793 \\
(96.1 \%) \\
{[3.9 \%]}\end{array}$ & $\begin{array}{c}5299 \\
(95.9 \%) \\
{[4.1 \%]}\end{array}$ \\
\hline $16-32$ & $\begin{array}{c}7091 \\
(98.5 \%) \\
{[1.5 \%]}\end{array}$ & $\begin{array}{c}13123 \\
(99.5 \%) \\
{[0.5 \%]}\end{array}$ & $\begin{array}{c}1839 \\
(98.8 \%) \\
{[1.2 \%]}\end{array}$ & $\begin{array}{c}3239 \\
(95.6 \%) \\
{[4.4 \%]}\end{array}$ & $\begin{array}{c}3954 \\
(99.4 \%) \\
{[0.6 \%]}\end{array}$ & $\begin{array}{c}4222 \\
(99.2 \%) \\
{[0.8 \%]}\end{array}$ & $\begin{array}{c}627 \\
(99.8 \%) \\
{[0.2 \%]}\end{array}$ & $\begin{array}{c}5647 \\
(98.9 \%) \\
{[1.1 \%]}\end{array}$ & $\begin{array}{c}2431 \\
(98.7 \%) \\
{[1.3 \%]}\end{array}$ \\
\hline $32-64$ & $\begin{array}{c}3369 \\
(99.5 \%) \\
{[0.5 \%]}\end{array}$ & $\begin{array}{c}7079 \\
(99.8 \%) \\
{[0.2 \%]}\end{array}$ & $\begin{array}{c}655 \\
(99.5 \%) \\
{[0.5 \%]}\end{array}$ & $\begin{array}{c}1242 \\
(98.4 \%) \\
{[1.6 \%]}\end{array}$ & $\begin{array}{c}1518 \\
(99.7 \%) \\
{[0.3 \%]}\end{array}$ & $\begin{array}{c}1448 \\
(99.9 \%) \\
{[0.1 \%]}\end{array}$ & $\begin{array}{c}208 \\
(99.5 \%) \\
{[0.5 \%]}\end{array}$ & $\begin{array}{c}2675 \\
(99.5 \%) \\
{[0.5 \%]}\end{array}$ & $\begin{array}{c}1013 \\
(99.6 \%) \\
{[0.4 \%]}\end{array}$ \\
\hline $64+$ & $\begin{array}{c}1416 \\
(99.7 \%) \\
{[0.3 \%]}\end{array}$ & $\begin{array}{c}3658 \\
(99.9 \%) \\
{[0.1 \%]}\end{array}$ & $\begin{array}{c}341 \\
(99.7 \%) \\
{[0.3 \%]}\end{array}$ & $\begin{array}{c}405 \\
(99.5 \%) \\
{[0.5 \%]}\end{array}$ & $\begin{array}{c}577 \\
(100 \%) \\
{[0 \%]}\end{array}$ & $\begin{array}{c}529 \\
(100 \%) \\
{[0 \%]}\end{array}$ & $\begin{array}{c}85 \\
(100 \%) \\
{[0 \%]}\end{array}$ & $\begin{array}{c}1259 \\
(99.8 \%) \\
{[0.2 \%]}\end{array}$ & $\begin{array}{c}599 \\
(99.8 \%) \\
{[0.2 \%]}\end{array}$ \\
\hline
\end{tabular}

the nine climatic zones are depicted in Fig. 2a. The total number of rainy pixels observed in each rain rate interval along with the occurrence (in \%) of the different kinds of precipitating systems are listed in Table 1. At each rain rate interval, the mean $D_{m}$ was estimated only when the number of data points was over 100. The segregated mean $D_{m}$ values depicted in Fig. 2a showed large spatial variability over the Indian subcontinent during the SWM season. As $R$ increased, $D_{m}$ also increased in all the regions, but the rate of increase was different in different regions. The differences in $D_{m}$ were not apparent at the first two rain rate intervals $\left(R<2 \mathrm{~mm} \mathrm{~h}^{-1}\right)$ due to the truncation of the dataset with $D_{m}<1 \mathrm{~mm}$. At any given $R$, the $D_{m}$ values were the largest over the SEPI and NWI regions, followed by the $\mathrm{FHH}, \mathrm{CI}$, the $\mathrm{BOB}$, and NEI, and were the smallest over the $\mathrm{MC}, \mathrm{WG}$, and $\mathrm{AS}$ regions. This indicated the presence of more bigger drops and/or fewer smaller drops in the continental systems than in the maritime precipitating systems (Rao et al. 2001; Tokay et al. 2002; Rosenfeld and Ulbrich 2003; Radhakrishna et al. 2009; Radhakrishna and Rao 2010; Lavanya et al. 2019). Within the continental precipitating systems, the number density was higher for the bigger drops and was lower for the smaller drops in the SEPI and NWI regions than in the FHH and CI regions. However, within the surrounding seas of India, the number density of smaller drops was high and was lower for larger drops over the AS than the $\mathrm{BOB}$ at all rain rates. In contrast to land and sea regions, the two coastal regions (WG and $\mathrm{MC}$ regions) had similar type of DSDs, but when compared to land regions and the $\mathrm{BOB}$, the smaller drops were engulfed. The small $D_{m}$ values observed over the AS and WG regions could be due the high occurrence of shallow systems that produce greater numbers of smaller drops, as they lack of sufficient time to grow before reaching the surface.

DSDs are distinctly different for deep and shallow rain, with a relatively larger number of smaller sized drops in shallow systems than in deep systems (Munchak et al. 2012). To study DSD variations in deep and shallow systems, the precipitating systems were divided into deep and shallow and the $D_{m}$ values 
were grouped based on $R$ for each type of system. The mean values of $D_{m}$ for the deep and shallow systems are depicted in Figs. $2 \mathrm{~b}$ and $2 \mathrm{c}$, respectively. The $R-$ $D_{m}$ curves of deep and shallow systems were the same for the AS and WG regions, which indicated that the DSDs of the deep and shallow systems over these regions were similar. For deep systems, at any given $R$, the number density of larger sized raindrops was higher and lower for smaller sized raindrops over the SEPI and NWI regions, respectively, than over other regions of Indian subcontinent, while the opposite was true for the AS, WG, and $\mathrm{MC}$ regions. On the other hand, for shallow storms, the change in mean $D_{m}$ with $R$ was minimal $(<0.2 \mathrm{~mm}$ ) in all regions (Fig. 2c). For shallow storms, at a given $R$, the $D_{m}$ values were the largest over the AS and BOB regions, followed by the WG, MC, FHH, and NEI, and were the smallest over the SEPI region. The $R-D_{m}$ curve for shallow rain (Fig. 2c) was present only at the first few rain rate intervals for the NWI and SEPI regions due to the lower occurrence of shallow storms with higher intensities (Table 1) over these regions (Houze et al. 2015; Saikranthi et al. 2013, 2014, 2018). For shallow storms, at a given $R$, the larger drops were observed more frequently in maritime systems than in continental systems, whereas the opposite was true for deep storms. DSDs of the deep and shallow systems were similar in the AS and WG regions.

The standard deviation of $D_{m}$ at each rain rate interval for different regions during the presence of different systems is shown in Fig. 3 to examine the statistical significance of the $D_{m}$ values at different rain rate intervals. The standard deviation of $D_{m}$ increased gradually from 0.3 to $0.5 \mathrm{~mm}$ as $R$ increased in all regions. However, its value was less than the difference in $D_{m}$ observed between the continental and maritime systems $(>0.7 \mathrm{~mm})$ during medium and high rain rates. The $R-D_{m}$ curves were similar in (1) the SEPI and NWI regions, (2) the FHH and CI regions, (3) the BOB and NEI regions, and (4) the AS and WG regions. These features could also be observed in the calculated probability values (P-values) at a $95 \%$ confidence level (not shown), which indicated similar $D_{m}$ values for (1) the CI and FHH regions, (2) the AS and WG regions, (3) the BOB and NEI regions, and (4) the SEPI and NWI regions and were distinctly different between continental, maritime, and orographic forced regions. Compared with the continental regions, the DSDs differed significantly between dry (NWI and SEPI) and wet (CI and $\mathrm{FHH}$ ) regions. In addition, differences in the DSDs were significant between the $\mathrm{BOB}$ and AS.
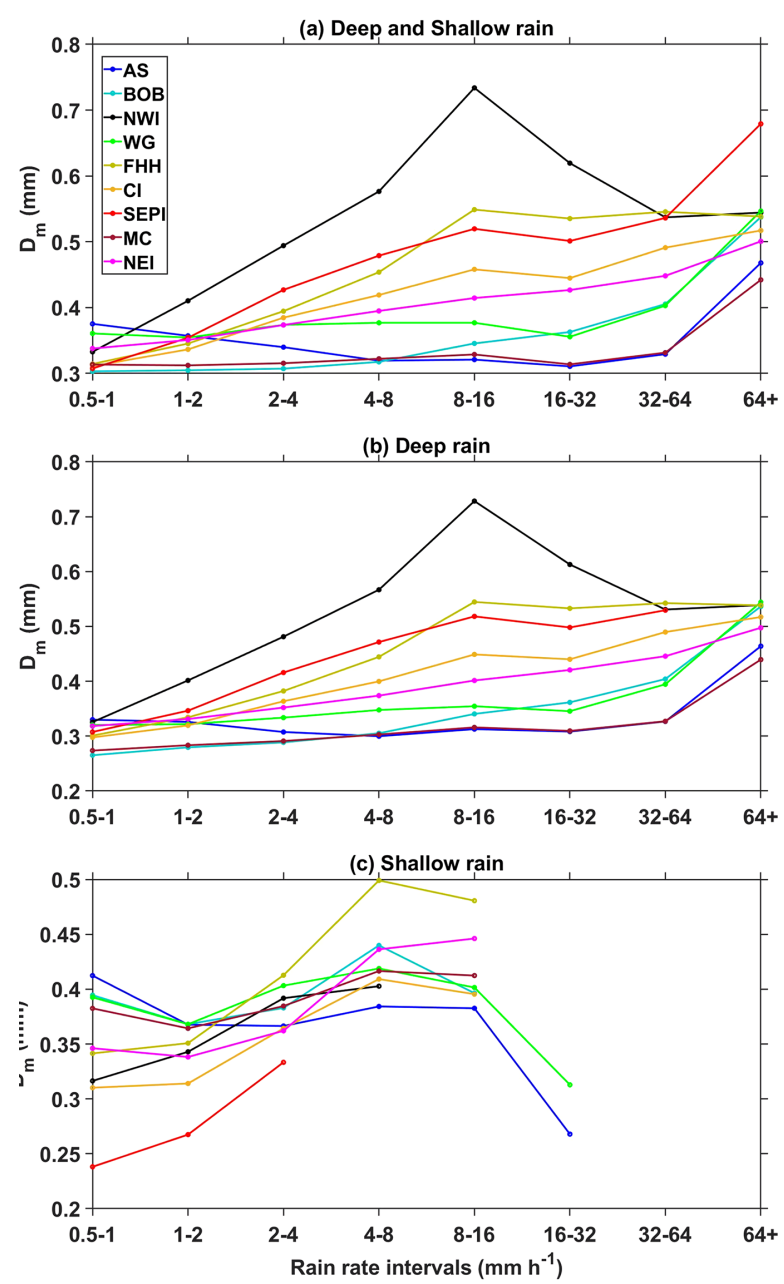

Fig. 3. (a) Standard deviation of near surface mean $D_{m}(\mathrm{~mm})$ shown Fig. 2, at different rain rate intervals obtained from GPM-DPR during the SWM season in different climatic zones. (b) and (c) are the same as (a), but for deep and shallow precipitating systems, respectively.

\section{Discussion}

Stochastic collections of cloud drops grow from cloud condensation nuclei, which results in the nonuniform growth of hydrometeors and produces particle size distribution. DSD differences and in turn variations in $D_{m}$ seen at the near surface can either originate at the cloud formation stage and/or during the descent of precipitation particles to the ground. The spatiotemporal variations in $D_{m}$ depend on the dominant microphysical and dynamical processes that occur during the descent of precipitation particles (Rosenfeld 
and Ulbrich 2003; Rao et al. 2009; Radhakrishna et al. 2009). The dominant processes that affect the shape and spectrum of DSDs were illustrated by Rosenfeld and Ulbrich (2003). For example, condensation/ vapor deposition and aggregation/riming/collisioncoalescence increase the size of hydrometeors, while evaporation/sublimation and breakup reduce them. Updrafts/downdrafts, advection by horizontal wind, and entrainment/detrainment processes are dynamical processes that affect $D_{m}$. Updrafts curb the smaller drops, which are carried to aloft by active convective cells and are then deposited into other regions of the mesoscale convective systems, where they later fall out. Thus, these smaller drops have enough time to grow by condensation/collision-coalescence processes and fall as either medium or large raindrops. Therefore, the concentration of medium- and large-sized raindrops increases at the expense of smaller raindrops. However, downdrafts increase the downward flux of the drops, where the density of the smaller drops increases more than the medium and larger raindrops.

MODIS provides the CER of ice, water, and mixed particles; however, the present study used the CER for liquid (Platnick 2000). The mean CER for liquid over different regions of the Indian subcontinent is shown in Fig. 4. The CER for liquid was larger for maritime clouds than for continental clouds, which is in good agreement with prior studies (Rosenfeld and Ulbrich 2003; Radhakrishna et al. 2009). The CER for liquid was large over the $\mathrm{AS}, \mathrm{BOB}, \mathrm{MC}, \mathrm{WG}$, and NEI regions and small over the NWI region. The large CER values observed over the WG, MC, and NEI regions could be due to the clouds formed due to the orographic lifting of maritime air mass carried by monsoonal winds (Fig. 1) from the surrounding seas. Within the land regions, the cloud particles were the largest over the FHH, followed by the CI and SEPI regions and were the smallest over the NWI region. The CER distribution and DSD at the near surface are shown in Figs. 2 and 4 and indicated that the maritime clouds contained larger cloud drops than the continental clouds, while the raindrop population at the near surface showed the exact opposite trend. Therefore, it can be concluded that the microphysical and dynamical processes that occur during the descent of precipitation particles play a vital role in modulating the $D_{m}$ observed at the near surface over land regions, corroborating the findings of Rao et al. (2009) and Radhakrishna et al. (2009).

To describe the dominant microphysical processes that occur in the descent of hydrometeors, the vertical

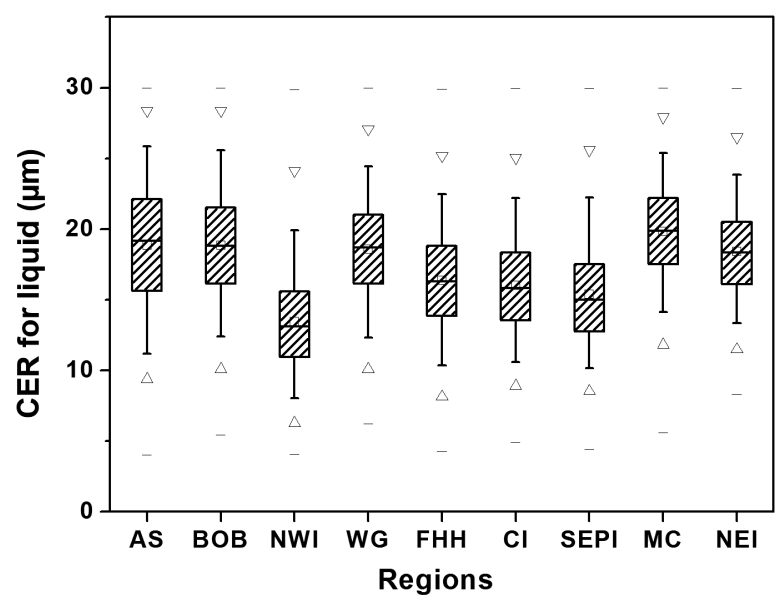

Fig. 4. Box plot of MODIS level-3 CER for liquid over different climatic zones of the Indian subcontinent during the SWM season. The central mark on each box represents the mean and the bottom and top edges of the box indicate the 25 th and 75 th percentiles, respectively. The bottom and top whiskers represent the 5th and 95th percentiles and the up and down direction triangles represent the 1st and 99th percentiles, respectively. The top and bottom dashes represent the maximum and minimum CER values, respectively.

profiles of reflectivity are considered for both deep and shallow systems, as depicted in Fig. 5. In deep systems (Fig. 5a), the reflectivity increased with decreasing altitude from 10 to $5 \mathrm{~km}$ in all regions. The growth rate of hydrometeors between $10 \mathrm{~km}$ and $7 \mathrm{~km}$ was approximately the same in all the regions, but was quite different from altitudes of $7 \mathrm{~km}$ to $5 \mathrm{~km}$. The growth rate was the highest over the $\mathrm{MC}$ region, followed by the NEI and BOB regions, and was the lowest over the SEPI region. Comparing the seas and adjacent orography regions, the growth rate was lower over the AS and WG than over the BOB and MC regions. A negative slope (from $4 \mathrm{~km}$ to $0.5 \mathrm{~km}$ altitude (i.e., from a top to bottom direction)) was observed in the median reflectivity profiles of deep systems below $4 \mathrm{~km}$ altitude in all regions, with the exceptions of the SEPI and NWI regions. This suggested that the predominance of low-level hydrometeor growth could be due to collision-coalescence processes over the AS, BOB, WG, MC, NEI, CI, and FHH regions. However, the rate of the collision-coalescence process was relatively different in these regions. The growth rate was highest over the WG, followed by the NEI, $\mathrm{MC}$, and AS regions, and was the lowest over the CI 
(a) Deep rain

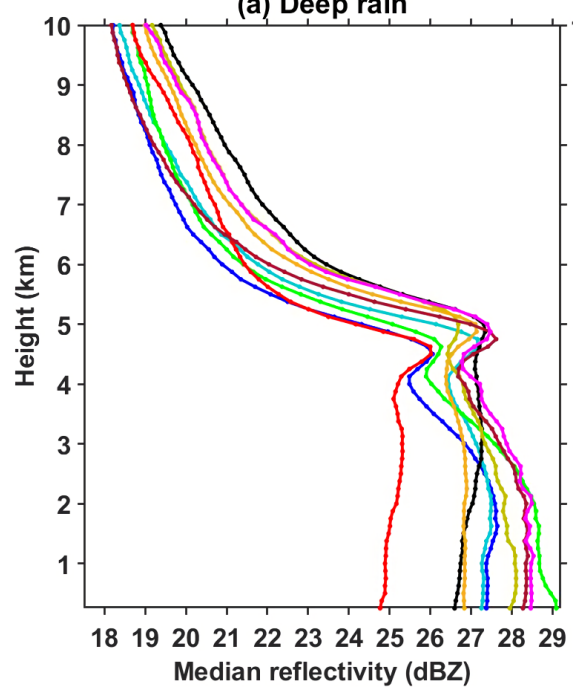

(b) Shallow rain

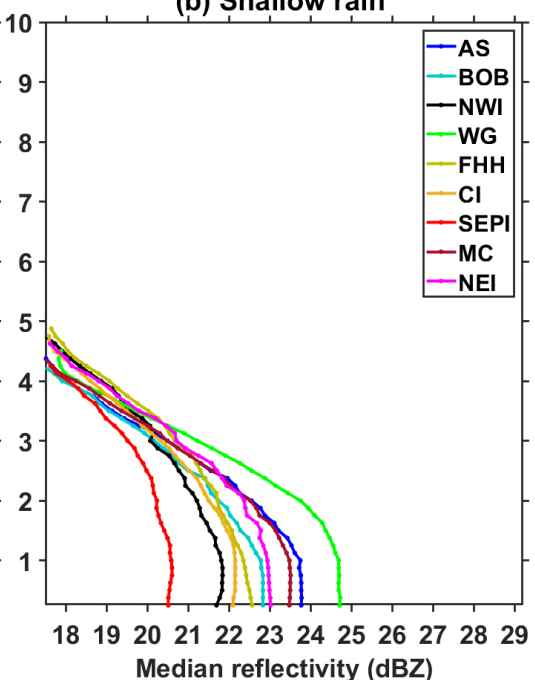

Fig. 5. Vertical profiles of median reflectivity derived from GPM-DPR during the presence of (a) deep systems and (b) shallow systems in the SWM season over different climatic zones of the Indian subcontinent.

region, where the collision-coalescence and breakup/ evaporation processes were nearly in equilibrium. The positive slopes observed over the SEPI and NWI regions indicated that the low-level hydrometeor size reduction could be due to evaporation and/or collisional breakup processes. The reflectivity profiles of shallow storms (Fig. 5b) showed negative slopes in all regions, which indicated low-level hydrometeor growth. Comparing the land regions with the sea and orography regions, the growth rate was less over the land regions and minimal over SEPI. In the absence of evaporation, the higher growth rate of raindrops resulted in larger $D_{m}$ values over the seas than over the land regions. This could be due to the prevalence of moist atmosphere at low levels over oceans that minimizes the evaporation rate and hence results in relatively large drops compared with land regions. The reflectivity profiles of the AS and WG regions (excluding the bright band region) indicated that the dominant hydrometer growth occurred below the melting region for both the deep and shallow systems. Therefore, the $D_{m}$ values observed for these two systems were also similar over these two regions (Figs. $2 b, c)$.

The vertical profile of the reflectivity (Fig. 5) was made by gathering the various precipitation systems at different stages. Though it provides a broad picture, the height variation of individual reflectivity profiles provides better insight into the dominant microphysical processes. For instance, to understand the dominant microphysical processes over different regions, Hirose and Nakamura (2004) used gradients in the rain rate of between $2 \mathrm{~km}$ and $3.5 \mathrm{~km}$ from the individual reflectivity profiles of the TRMM. In the present study, we adopted the same methodology and estimated the reflectivity gradients as being between $2 \mathrm{~km}$ and $3.5 \mathrm{~km}(\Delta \mathrm{Z})$ for each profile. A positive $\Delta \mathrm{Z}$ indicated the growth of the hydrometeor and a negative $\Delta \mathrm{Z}$ represented the decay of the hydrometeor. The cumulative distribution of $\Delta Z$ for deep and shallow rain over different climatic regions in India is depicted in Fig. 6. The cumulative distribution of $\Delta \mathrm{Z}$ showed that around $55-60 \%$ of profiles evidenced positive gradients for deep rain over the $\mathrm{AS}, \mathrm{BOB}, \mathrm{WG}, \mathrm{MC}$, and NEI (Fig. 6a), which indicated the dominance of hydrometeor growth through the collision-coalescence process. On the other hand, $\Delta \mathrm{Z}$ was negative for around $60-65 \%$ over NWI and SEPI, which indicated the decay of the hydrometeors as a result of the evaporation of rain drops. The growth and decay processes were nearly in equilibrium (about $50 \%$ ) over the FHH and CI regions. Regardless of the region, hydrometeor growth mechanisms were found to be dominant $(>70$ $\%$ of the time) during shallow rain. The rate of growth processes varied from one region to another. The growth rate was the highest over the WG region, followed by the NEI, MC, and AS regions, and was the lowest over the FHH and CI regions. The microphysical processes inferred from the above analysis (Fig. 6) are consistent with those obtained from the median 


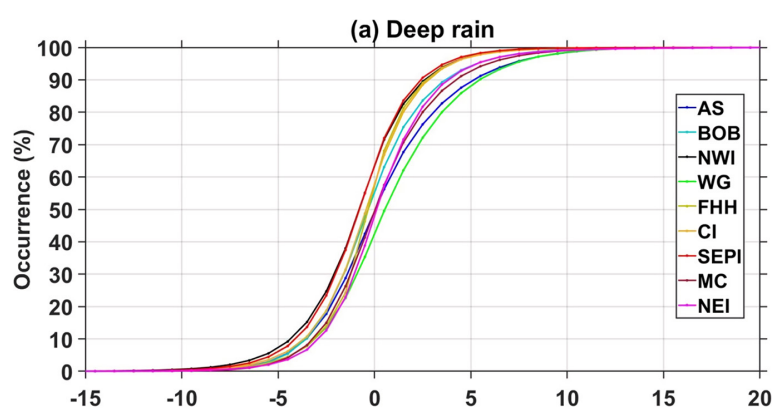

(b) Shallow rain

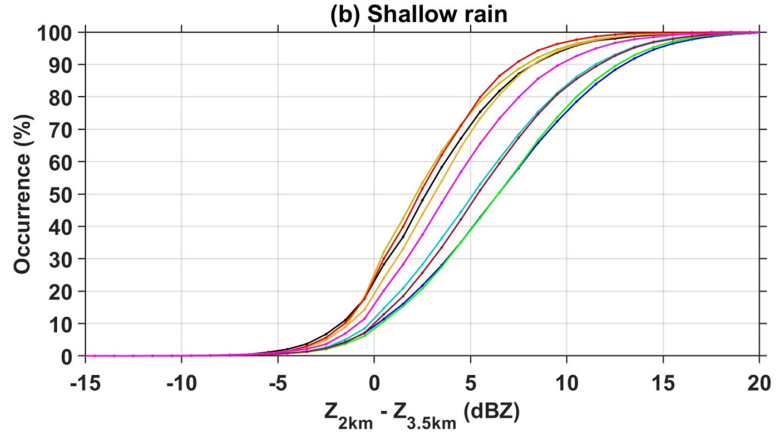

Fig. 6. Cumulative distribution of reflectivity gradients $\left(Z_{2 \mathrm{~km}}-Z_{3.5 \mathrm{~km}}\right.$ in dBZ) for (a) deep and (b) shallow rain obtained from GPM-DPR.

vertical profiles, as shown in Fig. 5.

Vertical velocity information was not available during the overpass times of GPM; therefore, convective rain was considered a proxy for the up- and downdrafts over a given region in studying the effects of vertical wind on DSDs. The occurrence and intensity of deep convective rain were higher over the land region than over the nearby seas (Romatschke et al. 2010; Saikranthi et al. 2014; Rao et al. 2016). This indicated that the occurrence, as well as the strength of updrafts, was higher in the continental clouds than in the maritime clouds.

Over the NWI and SEPI regions, although smaller sized cloud drops were abundant, the near surface DSD of deep systems showed fewer small drops and more large-sized raindrops. The evaporation process that occurred below $4 \mathrm{~km}$ altitude and the frequent convection (Saikranthi et al. 2014) together reduced the number of small-sized raindrops and increased the large raindrops, which in turn increased the $D_{m}$ values, as noticed in Fig. 2a and 2b. Similar to the NWI and SEPI regions, the frequent occurrence of convection and low-level hydrometeor growth in the FHH and $\mathrm{CI}$ regions could result in larger raindrops and fewer small raindrops, in turn resulting in large $D_{m}$ values. However, when compared to the NWI and SEPI regions, the evaporation was negligible in these two regions, which could result in smaller sized drops and small $D_{m}$ values. Compared to inland regions (except $\mathrm{NEI}$ ), the low-level hydrometeor growth was higher and the frequency of convective rain was lower over the BOB and NEI regions, which could result in considerable smaller drops and small $D_{m}$ values. Though the low-level hydrometeor growth was the same over the $\mathrm{AS}$ and $\mathrm{BOB}$ regions, the infrequent convection could result in a greater abundance of small drops over the AS than over the BOB. The DSDs of orographic forced rainfall systems possessed larger numbers of smaller sized drops (Rosenfeld and Ulbrich 2003) than the other types of rain systems, which is why the $D_{m}$ values were the smallest over the WG and MC regions.

For shallow precipitating systems, the larger cloud drops and the high growth rate of low-level hydrometeors over the AS and BOB resulted in more number of larger drops and large $D_{m}$ values than seen in other regions. The $D_{m}$ values were similar in the $\mathrm{WG}$ and MC regions, not only for the deep systems but also for the shallow systems; however, the deep and shallow systems' $D_{m}$ values were different. The low hydrometeor growth rates over land regions produced a profusion of smaller sized raindrops and resulted in smaller $D_{m}$ values than those over the sea and surrounding orographic regions.

\section{Conclusion}

Utilizing five years of GPM-DPR-retrieved DSD datasets, the present study characterized the variations in $D_{m}$ in deep and shallow precipitating systems over different climatic regions of the Indian subcontinent and the adjoining seas for the first time. The segregated $D_{m}$ dataset, which was based on $R$ during the principal rainy season (SWM), revealed the following: 1) At a given $R$, the $D_{m}$ values of deep systems were nearly equal for four groups of regions during the SWM season (i.e., for (1) the NWI and SEPI regions, (2) the $\mathrm{FHH}$ and $\mathrm{CI}$ regions, (3) the NEI and $\mathrm{BOB}$ regions, and (4) the $\mathrm{AS}, \mathrm{WG}$, and $\mathrm{MC}$ regions).

2) For a given intensity, the $D_{m}$ values were large for deep systems and small for shallow systems over the continent compared with the maritime precipitating systems. This indicated that there were more bigger raindrops in continental deep storms than in maritime deep storms and fewer in continental shallow storms than in the corresponding maritime storms.

3) The near surface $D_{m}$ values of the deep systems 
were the largest over the NWI and SEPI regions, which indicated the presence of more bigger raindrops and fewer small-sized raindrops than in other regions of the Indian subcontinent. However, the clouds over these regions showed larger CER values. Evaporation below $4 \mathrm{~km}$ altitude and the presence of updrafts together reduced the number of small-sized raindrops and permitted only large raindrops to fall. Thus, the observed $D_{m}$ values at any given $R$ were larger in these regions than in other regions of the Indian subcontinent. Nevertheless, relative to other regions, a lower hydrometeor growth rate produced more small-sized drops and subsequently small $D_{m}$ values in shallow storms over these regions.

4) The $D_{m}$ values over the FHH and CI indicated the presence of more number of larger drops and fewer small-sized drops than those over maritime and orographic systems. A high frequency of convection and a lower hydrometeor growth rate at low levels compared with maritime and orographic rain systems were responsible for the abovementioned features. However, for shallow storms, the $D_{m}$ values were smaller over these regions due to the presence of smaller cloud drops and a lower hydrometeor growth rate than those in maritime storms.

5) The storms formed over the northern BOB advect to the NEI region by monsoonal winds, such that the $D_{m}$ values observed over the BOB and NEI were identical. Comparing the maritime $D_{m}$ of the deep systems, the concentration of large drops was higher in the BOB than in the AS, though the DSDs were the same for the shallow storms. A high frequency of convection over the BOB was responsible for the observed $D_{m}$ differences between the AS and BOB.

6) The $D_{m}$ values of the deep systems were the smallest over the AS, MC, and WG regions, which indicated an abundance of small raindrops and fewer large-sized raindrops compared with the other regions. On the other hand, for shallow systems, the $D_{m}$ values were larger than the continental and smaller than the maritime shallow storms. This was due to the less evaporation and high growth rate of hydrometeors compared with maritime and continental shallow storms.

7) The $D_{m}$ values were similar for deep and shallow systems over the AS and WG regions. This was mainly due to the dominant low-level hydrometeor growth over these two regions for both systems.

\section{Acknowledgments}

The authors would like to thank the GPM (ftp:// arthurhou.pps.eosdis.nasa.gov) science team for providing the GPM-DPR dataset and the MODIS (https:// ladsweb.modaps.eosdis.nasa.gov/) science team for providing the CER dataset. Dr. K. Saikranthi would like to thank the Department of Science \& Technology (DST), India, for providing the financial support through the reference number DST/INSPIRE/04/2017/ 001185. The authors would like to thank the two anonymous reviewers for their critical reviews in improving the quality of the manuscript.

\section{References}

Atlas, D., C. W. Ulbrich, F. D. Marks, Jr., E. Amitai, and C. R. Williams, 1999: Systematic variation of drop size and radar-rainfall relations. J. Geophys. Res., 104, 61556169.

Awaka, J., M. Le, V. Chandrasekar, N. Yoshida, T. Higashiuwatoko, T. Kubota, and T. Iguchi, 2016: Rain type classification algorithm module for GPM dualfrequency precipitation radar. J. Atmos. Oceanic Technol., 33, 1887-1898.

Bringi, V. N., V. Chandrasekar, J. Hubbert, E. Gorgucci, W. L. Randeu, and M. Schoenhuber, 2003: Raindrop size distribution in different climatic regimes from disdrometer and dual-polarized radar analysis. J. Atmos. Sci., 60, 354-365.

Chakravarty, K., and P. E. Raj, 2013: Raindrop size distributions and their association with characteristics of clouds and precipitation during monsoon and postmonsoon periods over a tropical Indian station. Atmos. Res., 124, 181-189.

D'Adderio, L. P., G. Vulpiani, F. Porcù, A. Tokay, and R. Meneghini, 2018: Comparison of GPM Core Observatory and ground-based radar retrieval of mass-weighted mean raindrop diameter at midlatitude. J. Hydrometeor., 19, 1583-1598.

Gadgil, S., 2003: The Indian monsoon and its variability. Annu. Rev. Earth Planet. Sci., 31, 429-467.

Goswami, B. N., 2005: South Asian monsoon. Intraseasonal Variability in the Atmosphere-Ocean Climate System. Lau, W. K.-M., and D. E. Waliser (eds.), Praxis, Springer Berlin Heidelberg, 19-61.

Harikumar, R., S. Sampath, and V. S. Kumar, 2010: Variation of rain drop size distribution with rain rate at a few coastal and high altitude stations in southern peninsular India. Adv. Space Res., 45, 576-586.

Hirose, M., and K. Nakamura, 2004: Spatiotemporal variation of the vertical gradient of rainfall rate observed by the TRMM precipitation radar. J. Climate, 17, 3378-3397.

Hou, A. Y., R. K. Kakar, S. Neeck, A. A. Azarbarzin, C. D. 
Kummerow, M. Kojima, R. Oki, K. Nakamura, and T. Iguchi, 2014: The Global Precipitation Measurement mission. Bull. Amer. Meteor. Soc., 95, 701-722.

Houze, R. A., Jr., K. L. Rasmussen, M. D. Zuluaga, and S. R. Brodzik, 2015: The variable nature of convection in the tropics and subtropics: A legacy of 16 years of the Tropical Rainfall Measuring Mission satellite. Rev. Geophys., 53, 994-1021.

Huffman, G. J., D. T. Bolvin, E. J. Nelkin, and J. Tan, 2017: Integrated Multi-satellitE Retrievals for GPM (IMERG) technical documentation. IMERG Tech Document, 54 pp. [Available at https://pmm.nasa.gov/ sites/default/files/document_files/IMERG_technical_ doc_3_22_17.pdf.]

Kirankumar, N. V. P., T. N. Rao, B. Radhakrishna, and D. N. Rao, 2008: Statistical characteristics of raindrop size distribution in southwest monsoon season. J. Appl. Meteor. Climatol., 47, 576-590.

Konwar, M., S. K. Das, S. M. Deshpande, K. Chakravarty, and B. N. Goswami, 2014: Microphysics of clouds and rain over the Western Ghat. J. Geophys. Res.: Atmos., 119, 6140-6159.

Kozu, T., K. K. Reddy, S. Mori, M. Thurai, J. T. Ong, D. N. Rao, and T. Shimomai, 2006: Seasonal and diurnal variations of raindrop size distribution in Asian monsoon region. J. Meteor. Soc. Japan, 84A, 195-209.

Kulkarni, A., R. Kriplani, S. Sabade, and M. Rajeevan, 2011: Role of intra-seasonal oscillations in modulating Indian summer monsoon rainfall. Climate Dyn., 36, 1005-1021.

Lavanya, S., N. V. P. Kirankumar, S. Aneesh, K. V. Subrahmanyam, and S. Sijikumar, 2019: Seasonal variation of raindrop size distribution over a coastal station Thumba: A quantitative analysis. Atmos. Res., 229, 86-99.

Liao, L., R. Meneghini, and A. Tokay, 2014: Uncertainties of GPM DPR rain estimates caused by DSD parameterizations. J. Appl. Meteor. Climatol., 53, 2524-2537.

Maitra, A., 2004: Rain attenuation modeling from measurements of rain drop size distribution in the Indian region. IEEE Antennas and Wireless Propag. Lett., 3, 180-181.

Meneghini, R., H. Kumagai, J. R. Wang, T. Iguchi, and T. Kozu, 1997: Microphysical retrievals over stratiform rain using measurements from an airborne dualwavelength radar-radiometer. IEEE Trans. Geosci. Remote Sens., 35, 487-506.

Munchak, S. J., C. D. Kummerow, and G. Elsaesser, 2012: Relationships between the raindrop size distribution and properties of the environment and clouds inferred from TRMM. J. Climate, 25, 2963-2978.

Platnick, S., 2000: Vertical photon transport in cloud remote sensing problems. J. Geophys. Res., 105, 2291922935.

Platnick, S., K. G. Meyer, M. D. King, G. Wind, N. Amarasinghe, B. Marchant, G. T. Arnold, Z. Zhang, P. A.
Hubanks, R. E. Holz, P. Yang, W. L. Ridgway, and J. Riedi, 2017: The MODIS cloud optical and microphysical products: Collection 6 updates and examples from Terra and Aqua. IEEE Trans. Geosci. Remote Sens., 55, 502-525.

Radhakrishna, B., and T. N. Rao, 2009: Statistical characteristics of multipeak raindrop size distributions at the surface and aloft in different rain regimes. Mon. Wea. Rev., 137, 3501-3518.

Radhakrishna, B., and T. N. Rao, 2010: Differences in cyclonic raindrop size distribution from southwest to northeast monsoon season and from that of noncyclonic rain. J. Geophys. Res., 115, D16205, doi:10.1029/ 2009JD013355.

Radhakrishna, B., T. N. Rao, D. N. Rao, N. P. Rao, K. Nakamura, and A. K. Sharma, 2009: Spatial and seasonal variability of raindrop size distributions in southeast India. J. Geophys. Res., 114, D04203, doi:10.1029/ 2008JD011226.

Radhakrishna, B., S. K. Satheesh, T. N. Rao, K. Saikranthi, and K. Sunilkumar, 2016: Assessment of DSDs of GPM-DPR with ground-based disdrometer at seasonal scale over Gadanki, India. J. Geophys. Res.: Atmos., 121, 11792-11802.

Rajeevan, M., S. Gadgil, and J. Bhate, 2010: Active and break spells of the Indian summer monsoon. J. Earth Syst. Sci., 119, 229-247.

Rao, T. N., D. N. Rao, K. Mohan, and S. Raghavan, 2001: Classification of tropical precipitating systems and associated $Z-R$ relationships. J. Geophys. Res., 106, 17699-17711.

Rao, T. N., B. Radhakrishna, K. Nakamura, and N. P. Rao, 2009: Differences in raindrop size distribution from southwest monsoon to northeast monsoon at Gadanki. Quart. J. Roy. Meteor. Soc., 135, 1630-1637.

Rao, T. N., K. Saikranthi, B. Radhakrishna, and S. V. B. Rao, 2016: Differences in the climatological characteristics of precipitation between active and break spells of the Indian summer monsoon. J. Climate, 29, 7797-7814.

Reddy, K. K., and T. Kozu, 2003: Measurements of raindrop size distribution over Gadanki during south-west and north-east monsoon. Indian J. Radio Space Phys., 32, 286-295.

Romatschke, U., S. Medina, and R. A. Houze, Jr., 2010: Regional, seasonal, and diurnal variations of extreme convection in the South Asian region. J. Climate, 23, 419-439.

Rose, C. R., and V. Chandrasekar, 2006: A GPM dualfrequency retrieval algorithm: DSD profile-optimization method. J. Atmos. Oceanic Technol., 23, 13721383.

Rosenfeld, D., and C. W. Ulbrich, 2003: Cloud microphysical properties, processes, and rainfall estimation opportunities. Radar and Atmospheric Science: A Collection of Essays in Honor of David Atlas. Wakimoto 
Ramesh, R. M., and R. Srivastava (eds.), Meteor. Monogr., 30, 237-258.

Saikranthi, K., T. N. Rao, B. Radhakrishna, and S. V. B. Rao, 2013: Impact of misrepresentation of freezinglevel height by the TRMM algorithm on shallow rain statistics over India and adjoining oceans. J. Appl. Meteor. Climatol., 52, 2001-2008.

Saikranthi, K., T. N. Rao, B. Radhakrishna, and S. V. B. Rao, 2014: Morphology of the vertical structure of precipitation over India and adjoining oceans based on long-term measurements of TRMM PR. J. Geophys. Res.: Atmos., 119, 8433-8449.

Saikranthi, K., B. Radhakrishna, S. K. Satheesh, and T. N. Rao, 2018: Spatial variation of different rain systems during El Niño and La Niña periods over India and adjoining ocean. Climate Dyn., 50, 3671-3685.

Saikranthi, K., B. Radhakrishna, T. N. Rao, and S. K. Satheesh, 2019a: Differences in the association of sea surface temperature-precipitating systems over the Bay of Bengal and the Arabian Sea during southwest monsoon season. Int. J. Climatol., 39, 4305-4312.

Saikranthi, K., B. Radhakrishna, T. N. Rao, and S. K. Satheesh, 2019b: Variability in vertical structure of precipitation with sea surface temperature over the Arabian Sea and the Bay of Bengal as inferred by Tropical Rainfall Measuring Mission precipitation radar measurements. Atmos. Chem. Phys., 19, 10423-10432.

Seto, S., and T. Iguchi, 2011: Applicability of the iterative backward retrieval method for the GPM Dual-frequency Precipitation Radar. IEEE Trans. Geosci.
Remote Sens., 49, 1827-1838.

Seto, S., T. Iguchi, and T. Oki, 2013: The basic performance of a precipitation retrieval algorithm for the Global Precipitation Measurement mission's single/dualfrequency radar measurements. IEEE Trans. Geosci. Remote Sens., 51, 5239-5251.

Suresh, R., and A. K. Bhatnagar, 2005: Seasonal variability of raindrop size distribution over Cuddalore, a coastal station in Tamilnadu of southern peninsular India. Mausam, 56, 643-658.

Testud, J., S. Oury, R. A. Black, P. Amayenc, and X. Dou, 2001: The concept of "normalized" distribution to describe raindrop spectra: A tool for cloud physics and cloud remote sensing. J. Appl. Meteor., 40, 11181140.

Tokay, A., A. Kruger, W. F. Krajewski, P. A. Kucera, and A. J. P. Filho, 2002: Measurements of drop size distribution in the southwestern Amazon basin. J. Geophys. Res., 107, 8052, doi:10.1029/2001JD000355.

Tokay, A., L. P. D'Adderio, F. Porcù, D. B. Wolff, and W. A. Petersen, 2017: A field study of footprint-scale variability of raindrop size distribution. J. Hydrometeor, 18, 3165-3179.

Ulbrich, C. W., and D. Atlas, 2007: Microphysics of raindrop size spectra: Tropical continental and maritime storms. J. Appl. Meteor. Climatol., 46, 1777-1791.

Verma, A., and K. K. Jha, 1996: Rain drop size distribution model for Indian culture. Indian J. Radio Space Phys., 25, 15-21. 